\title{
WILEY-VCH
}

\section{Giant and reversible inverse barocaloric effects near room temperature in ferromagnetic $\mathrm{MnCoGeB}_{0.03}$}

\author{
A. Aznar ${ }^{1}$, P. Lloveras ${ }^{1,2}$, J. Kim², E. Stern-Taulats², M. Barrio ${ }^{1}$, J.-Ll. Tamarit ${ }^{1}$, \\ C.-F. Sánchez-Valdés ${ }^{3}$, J.-L. Sánchez Llamazares ${ }^{4, \dagger}$, N. D. Mathur² and X. Moya ${ }^{2, *}$
}

${ }^{1}$ Grup de Caracterització de Materials, Departament de Física, EEBE and Barcelona Research Center in Multiscale Science and Engineering, Universitat Politècnica de Catalunya, Eduard Maristany, 10-14, 08019 Barcelona, Catalonia, Spain

${ }^{2}$ Department of Materials Science, University of Cambridge, Cambridge, CB3 OFS, UK

${ }^{3}$ División Multidisciplinaria, Ciudad Universitaria, Universidad Autónoma de Ciudad Juárez (UACJ), calle José de Jesús Macías Delgado \#18100, Ciudad Juárez 32579, Chihuahua, México

${ }^{4}$ Instituto Potosino de Investigación Científica y Tecnológica A.C., Camino a la Presa San José No 2055, Col. Lomas $4^{a}$ sección, San Luis Potosí, S.L.P. 78216, México

† Correspondence to: jose.sanchez@ipicyt.edu.mx

* Correspondence to: xm212@cam.ac.uk

In the last three decades, numerous reports of giant magnetocaloric (MC) effects near room-temperature first-order magnetostructural phase transitions have led to proposals for environmentally friendly cooling ${ }^{1-10}$. However, there are two matters arising. First, giant and reversible changes of isothermal entropy $\Delta S$ and adiabatic temperature $\Delta T$ necessitate large changes of magnetic field $\Delta H$ that are challenging to generate economically. Second, most giant MC materials display magnetostructural transitions in which large changes in volume can lead to cracking and also complete mechanical failure ${ }^{11-15}$. By contrast, it is straightforward to generate large changes of hydrostatic pressure $\Delta p$ in order to drive giant barocaloric (BC) effects ${ }^{9,10,16}$ near non-isochoric magnetostructural phase transitions ${ }^{17-23}$, and it is straightforward to maintain the mechanical integrity of a BC working body by encapsulating it together with its pressure-transmitting medium. Here we use variable-pressure calorimetry to investigate giant $\mathrm{BC}$ effects in a well-known MC material ${ }^{24,25}$ that is brittle, namely $\mathrm{MnCoGeB}_{0.03}$ near the $\sim 290 \mathrm{~K}$ paramagnetic/hexagonal-to-ferromagnetic/orthorhombic (PM/H to $\mathrm{FM} / \mathrm{O}$ ) phase transition, 


\section{WILEY-VCH}

which is associated with a giant increase of volume $(\sim 4 \%)$ that causes a complete mechanical failure that would be problematic in MC cooling devices ${ }^{26}$. Moderate changes of applied pressure $(|\Delta p| \sim 1.7 \mathrm{kbar})$ drive giant and reversible MC effects of $|\Delta S| \sim 30 \mathrm{~J} \mathrm{~K}^{1} \mathrm{~kg}^{-1}$ and $|\Delta T| \sim 10 \mathrm{~K}$. These BC effects are similar to the MC effects that would require impractically large changes of magnetic field $\left(\mu_{0} \Delta H \sim 10 \mathrm{~T}\right.$ ) in order to be reversible ( $\mu_{0}$ is the permeability of free space). Our study therefore shows that hydrostatic pressure represents an inexpensive and practical method of driving caloric effects in brittle MC materials. More generally, our study incorporates MnCoGe-based compounds into the growing family of multicaloric materials ${ }^{27}$.

Above the magnetostructural transition temperature of $T_{0} \sim 290 \mathrm{~K}, \mathrm{MnCoGeB}_{0.03}$ adopts the $\mathrm{PM} / \mathrm{H}$ phase $\left(P 63 / m m c \text { or } \mathrm{Ni}_{2} \text { In-type space group }\right)^{24}$. On cooling the sample through the transition, $\mathrm{MnCoGeB}_{0.03}$ typically comprises a mixture of the majority FM/O phase (Pnma or TiNiSi-type space group), and a minority $\mathrm{PM} / \mathrm{H}$ phase that is favoured in boron-rich regions ${ }^{24}$. Large changes of magnetisation $M$ associated with this magnetostructural transition permit a giant conventional MC effect ${ }^{24}$ of $\Delta S \sim-38 \mathrm{~J} \mathrm{~K}^{1} \mathrm{~kg}^{-1}$ when applying $\mu_{0} H=5 \mathrm{~T}$. However, larger field changes would be required to drive this MC effect in a reversible manner because the transition temperature barely shifts with magnetic field ${ }^{21,28,29}$, and the aforementioned value of $\mu_{0} \Delta H \sim 10 \mathrm{~T}$ was calculated using a typical value of $\left|\mathrm{d} T / \mu_{0} \mathrm{~d} H\right| \sim 2 \mathrm{~K} \mathrm{~T}^{-1}$, a transition width $^{24}$ of $\sim 10 \mathrm{~K}$, and a thermal hysteresis ${ }^{24}$ of $\sim 10 \mathrm{~K}$. Here we overcome both the large-field and brittle-fracture issues by using moderate changes in hydrostatic pressure to reversibly drive giant caloric effects in $\mathrm{MnCoGeB}_{0.03}$.

Magnetometry, calorimetry and scanning electron microscopy were performed on samples \#1-3 (see Experimental Section) because of the virgin effects and mechanical breakdown that arose with thermal cycling ${ }^{25,30,31}$. Measurements of low-field magnetization in sample \#1 show that the PM/H-FM/O transition is broad during the first cooling run [Figure 1(a)]. Measurements of $\mathrm{d} Q /|\mathrm{d} T|$ in sample \#2 during the first cooling run confirm that the transition is broad [Figure 1(b)], and reveal that it takes place in steps (heat $Q$ was obtained after baseline subtraction, $T$ is temperature). Both the broadness and step-like character of the transition imply that the motion of phase boundaries ${ }^{32}$ was pinned via the formation of cracks, whose presence was confirmed in sample \#3 using room-temperature scanning electron microscopy after the first cooling run [Figure 1(a) inset]. 


\section{WILEY-VCH}

Subsequent thermal cycling of the unclamped sample fragments [Figure 1(a,b)] increased the sharpness and smoothness of the transition, and reduced its thermal hysteresis. We therefore used $d Q /|d T|$ from the first heating run and the second cooling run to identify the transition start and finish temperatures on heating ( $\left.T_{\text {heat1 }} \sim 292 \mathrm{~K}, T_{\text {heat2 }} \sim 305 \mathrm{~K}\right)$ and cooling $\left(T_{\text {cool1 }} \sim\right.$ $\left.287 \mathrm{~K}, T_{\text {cool2 }} \sim 274 \mathrm{~K}\right)$; the peak value of $\mathrm{dQ} /|\mathrm{d} T|$ on heating $\left(T_{\text {heat }} \sim 299 \mathrm{~K}\right)$ and cooling ( $\left.T_{\text {cool }} \sim 281 \mathrm{~K}\right)$; a thermal hysteresis of $T_{\text {heat }}-T_{\text {cool }} \sim 18 \mathrm{~K}$; and a latent heat of $\left|Q_{0}\right| \sim 13.6 \mathrm{~kJ} \mathrm{~kg}^{-1}$ that is similar to literature values for alloys of similar composition ${ }^{24}$. Further thermal cycling had nominally no effect on all of these values.

Temperature-dependent x-ray diffraction performed on sample \#4 after the aforementioned virgin effect confirmed the expected ${ }^{24,33}$ changes in crystal structure [Figure 2(a) and Figure S1]. On heating through the phase transition, the unit-cell volume $V$ decreases by $\Delta V_{0}=-6.2 \pm 0.5 \AA^{3}$ [Figure 2(b)]. This $\sim 4 \%$ decrease of volume is large for magnetic alloys $^{17-22}$, and presages giant inverse BC effects ${ }^{9}$. By contrast, the BC effects that could be achieved in each phase ${ }^{34}$ will be negligible, owing to small volume thermal expansivity [Figure 2(b)].

Calorimetric measurements of $\mathrm{d} Q / \mathrm{d} T$ for sample \#4 confirmed the expected ${ }^{35}$ values of specific heat capacity $c \sim 420 \mathrm{~kJ} \mathrm{~K}^{-1} \mathrm{~kg}^{-1}$ at temperatures above and below the phase transition [Figure 2(c)]. They also permitted identifying the transition temperatures on heating ( $\left.T_{\text {heat1 }} \sim 294 \mathrm{~K}, T_{\text {heat2 }} \sim 305 \mathrm{~K}, T_{\text {heat }} \sim 299 \mathrm{~K}\right)$ and cooling $\left(T_{\text {cool1 }} \sim 290 \mathrm{~K}, T_{\text {cool2 }} \sim 282 \mathrm{~K}\right.$, $\left.T_{\text {cool }} \sim 286 \mathrm{~K}\right)$, and a thermal hysteresis of $\sim 13 \mathrm{~K}$. Integration of $(\mathrm{d} Q / \mathrm{d} T) / T$ measured on heating and cooling yielded the entropy $S^{\prime}(T)=S(T)-S(200 \mathrm{~K})$ on heating and cooling [Figure 2(d)], via $S^{\prime}(T)=S(T)-S(200 \mathrm{~K})=\int_{200 \mathrm{~K}}^{T}(1 / T)\left(\mathrm{d} Q / \mathrm{d} T^{\prime^{\prime}}\right) \mathrm{d} T^{\prime}$. The entropy change of $\left|\Delta S_{0}\right| \sim 47 \mathrm{~J} \mathrm{~K}^{-1} \mathrm{~kg}^{-1}$ for the hysteretic transition was found to be large ${ }^{36}$, in good agreement with the latent heat of sample \#2 via $\left|\Delta S_{0}\right| \sim\left|Q_{0}\right| / T_{0} \sim 47 \mathrm{~J} \mathrm{~K}^{-1} \mathrm{~kg}^{-1}$, and with previous experimental values ${ }^{24}$.

Measurements of $\mathrm{d} Q / \mathrm{d} T$ under applied pressure, which we present as $\mathrm{d} Q /|\mathrm{d} T|$ [Figure 3(a)], reveal that our transition temperatures vary strongly with pressure $\left[\mathrm{d} T_{\text {heat }} / \mathrm{d} p \sim \mathrm{d} T_{\text {cool }} / \mathrm{d} p \sim-10 \mathrm{~K} \mathrm{kbar}^{-1}\right.$, Figure 3(b)]. A similar shift of the anhysteretic transition temperature $\mathrm{d} T_{0} / \mathrm{d} p \sim-10 \mathrm{~K} \mathrm{kbar}^{-1}$ was obtained via the Clausius-Clapeyron equation $\mathrm{d} T_{0} / \mathrm{d} p=\Delta V_{0} / \Delta S_{0}$ using atmospheric-pressure specific volume change $\Delta V_{0} \sim 5 \mathrm{~mm}^{3} \mathrm{~g}^{-1}$ 


\section{WILEY-VCH}

[Figure 2(b)] and $\left|\Delta S_{0}\right| \sim 47 \mathrm{~J} \mathrm{~K}^{-1} \mathrm{~kg}^{-1}$ [Figure 2(d)]. These shifts are amongst the largest in magnitude observed for any BC material ${ }^{17-23,34,37-41}$, and would permit the full transition of width $T_{\mathrm{h} 2}-T_{\mathrm{h} 1} \sim 13 \mathrm{~K}$ to be fully driven in either direction using $|\Delta p|=\left|p-p_{\text {atm }}\right| \sim|p| \sim 1.3 \mathrm{kbar}$, where atmospheric pressure $p_{\text {atm }} \sim 0$ kbar. Integration of $(\mathrm{d} Q /|\mathrm{d} T|) / T$ at finite pressure reveals that the entropy change $\left|\Delta S_{0}\right|$ associated with the transition undergoes a significant decrease with increasing pressure (at a rate of $\sim-6.5 \mathrm{~J} \mathrm{~K} \mathrm{~kg}^{-1} \mathrm{kbar}^{-1}$ ) [Figure 3(c)], implying via the Clausius-Clapeyron equation a pressure-induced suppression of $\left|\Delta V_{0}\right|$ [Figure 3(d)]. The decrease in $\left|\Delta S_{0}\right|$ with increasing pressure arises because of the decrease in $\left|\Delta S_{0}\right|$ with reducing temperature [ref. ${ }^{35}$ and Supporting Figure S2] and the negative shift in our transition temperatures. (After cooling at atmospheric pressure or applied pressure, measurements of $\mathrm{d} Q /|\mathrm{d} T|$ on heating under applied pressure yield similar values of $\left|\Delta S_{0}\right|$ [Supporting Note 1], indicating that the FM/O:PM/H polymorph ratio on cooling through the transition is nominally independent of pressure.)

By combining the values of $\mathrm{d} Q /|\mathrm{d} T|$ that we measured under atmospheric pressure [Figure 2(c)] and applied pressure [Figure 3(a)], we calculated $S^{\prime}(T, p)=S(T, p)-S(200 \mathrm{~K}, 0)$ using:

$$
\left\{\begin{array}{lr}
\int_{200 \mathrm{~K}}^{T} \frac{c_{\mathrm{FM} / \mathrm{O}}}{T^{\prime}} \mathrm{d} T^{\prime} & T \leq T_{1} \\
\int_{200 \mathrm{~K}}^{T_{1}} \frac{c_{\mathrm{FM} / \mathrm{O}}}{T} \mathrm{~d} T+\int_{T_{1}}^{T} \frac{1}{T^{\prime}}\left(c_{\mathrm{FM} / \mathrm{O}-\mathrm{PM} / \mathrm{H}^{+}}+\left|\frac{\mathrm{d} Q}{\mathrm{~d} T^{\prime}}\right|_{p}\right) \mathrm{d} T^{\prime} & T_{1} \leq T \leq T_{2} \\
\int_{250 \mathrm{~K}}^{T_{1}} \frac{c_{\mathrm{FM} / \mathrm{O}}}{T} \mathrm{~d} T+\int_{T_{1}}^{T_{2}} \frac{1}{T}\left(c_{\mathrm{FM} / \mathrm{O}-\mathrm{PM} / \mathrm{H}^{+}}\left|\frac{\mathrm{d} Q}{\mathrm{~d} T}\right|_{p}\right) \mathrm{d} T+\int_{T_{2}}^{T} \frac{c_{\mathrm{PM} / \mathrm{H}} \mathrm{d} T^{\prime}}{T^{\prime}} & T_{2} \leq T
\end{array}\right.
$$

where $T_{1}$ is the transition start temperature, $T_{2}$ is the transition finish temperature, $C_{\mathrm{FM} / \mathrm{O}}$ is the specific heat capacity of the $\mathrm{FM} / \mathrm{O}$ phase outside the transition region, $C_{\mathrm{PM} / \mathrm{H}}$ is the specific heat capacity of the $\mathrm{PM} / \mathrm{H}$ phase outside the transition region, and $c_{\mathrm{FM} / \mathrm{O}-\mathrm{PM} / \mathrm{H}}=(1-\chi) \mathrm{C}_{\mathrm{FM} / \mathrm{O}}+\chi C_{\mathrm{PM} / \mathrm{H}}$ represents the specific heat capacity inside the transition region, where the transformed fraction $x$ on crossing the FM/O-PM/H transition was calculated using $x=\left[\int_{T_{1}}^{T}\left(\left|\mathrm{~d} Q / \mathrm{d} T^{\prime}\right|\right) \mathrm{d} T^{\prime}\right] /\left[\int_{T_{1}}^{T_{2}}(|\mathrm{~d} Q / \mathrm{d} T|) \mathrm{d} T\right]$. Note that near the transition, $C_{\mathrm{FM} / \mathrm{O}}$ is assumed to be independent of pressure, whereas $C_{\mathrm{PM} / \mathrm{H}}$ was necessarily pressure-dependent in order to ensure continuity in $S^{\prime}(T, p)$ [Figure 4(a,b)]. 


\section{WILEY-VCH}

By following isothermal trajectories in $S^{\prime}(T, p)$ [Figure 4(a)], we were able to evaluate the corresponding $\mathrm{BC}$ effects $\Delta S(T, \Delta p)$ [Figure 4(b)]. Our largest reversible value of $|\Delta S| \sim 30 \mathrm{~J} \mathrm{~K}^{-1} \mathrm{~kg}^{-1}$ arose at $T \sim 285 \mathrm{~K}$ using $|\Delta p| \sim 1.7$ kbar [Figure 4(b)], which compares favourably with other BC materials that are magnetic ${ }^{17-22}$ (Supporting Table 1). This value of $|\Delta S| \sim 30 \mathrm{~J} \mathrm{~K}^{-1} \mathrm{~kg}^{-1}$ also compares well with other BC solids ${ }^{34,37-41}$ when normalizing by volume to yield $|\Delta S| \sim 0.25 \mathrm{~J} \mathrm{~K}^{-1} \mathrm{~cm}^{-3}$ (Supporting Table 1), assuming a density of $8000 \mathrm{~kg} \mathrm{~m}^{-}$ ${ }^{3}$, obtained from lattice parameters [Figure 2(b) and S1(b)]. Importantly, the large shift of transition temperatures with pressure [Figure 3(b)] permits large entropy changes to be driven over a wide range of temperatures. For example, values of $|\Delta S| \sim 20 \mathrm{~J} \mathrm{~K}^{-1} \mathrm{~kg}^{-1}$ can be reversibly driven over a temperature span of $25 \mathrm{~K}$ using $|\Delta p| \sim 3.7$ kbar [Figure 4(b)].

Similarly, by following adiabatic trajectories in $S^{\prime}(T, p)$ [Figure 4(a,b)], we were able to evaluate $\Delta T\left(T_{\mathrm{s}}, \Delta p\right)$ on applying pressure $p$ at starting temperature $T_{\mathrm{s}}$ [Figure 4(d)], and $\Delta T\left(T_{\mathrm{f}}, \Delta p\right)$ on removing pressure $p$ to reach finishing temperature $T_{\mathrm{f}}$ [Figure 4(e)]. Our largest value of $|\Delta T| \sim 15 \mathrm{~K}$ arose at $T_{\mathrm{s}} \sim 286 \mathrm{~K}$ using $|\Delta p| \sim 3 \mathrm{kbar}$, with reversibility guaranteed for starting temperatures that lay below the thermally hysteretic regime for $T_{\mathrm{s}}<T_{\text {cool1 }}$, such that a pressure-induced temperature change of $\Delta T<0$ at $T_{\mathrm{s}}$ may be followed on pressure removal by a temperature change $\Delta T>0$ of the same magnitude, starting at the decreased temperature of $T_{\mathrm{S}}-|\Delta T|$. Smaller applied pressure permits smaller adiabatic temperature changes, with e.g. values of $|\Delta T| \sim 10 \mathrm{~K}$ using $|\Delta p| \sim 1.7 \mathrm{kbar}$. These BC effects significantly exceed the BC effects of $|\Delta T| \leq 8 \mathrm{~K}$ that have been achieved ${ }^{17-23}$ by using similar values of $|\Delta p|$ to drive magnetostructural phase transitions in other magnetic alloys near room temperature.

Our observation of near-room-temperature giant and reversible BC effects in the notoriously brittle $\mathrm{MC}$ compound $\mathrm{MnCoGeB}_{0.03}$ should inspire the study of $\mathrm{BC}$ effects in other brittle $\mathrm{MC}$ materials. BC effects are perfectly viable in powders that lie within pressure-transmitting media, such that fracture represents an advantage in terms of heat transfer. Our work could therefore stimulate the development of BC cooling devices based on traditional MC materials that are brittle. In contrast with MC cooling, there is no need to generate large magnetic fields at great expense; there is no need to mechanically stabilize brittle alloys with a polymer of low thermal conductivity ${ }^{26}$; and reversible caloric effects can be driven over a wide range of starting temperatures (away from the hysteretic regime) given that transition temperatures are so sensitive to pressure. 


\section{Experimental Section}

We used high purity elements from Alfa Aesar (Mn 99.9998\%, Ge 99.9999\%, Co 99.95\%, B 99.4\%) to prepare two alloys of nominal composition $\mathrm{MnCoGeB}_{0.03}$ by arc-melting under argon. Each alloy was melted three times to promote chemical homogeneity, encapsulated in a quartz tube under vacuum, annealed at $1123 \mathrm{~K}$ for five days, and finally quenched in water. The mass of the each resulting alloy was $\sim 3 \mathrm{~g}$. For the first alloy, a small needle-like piece ( $\sim 0.1 \mathrm{mg}$, sample \#1) was cut in order to perform temperature-dependent magnetometry at ambient pressure, and the large remaining piece (sample \#2) was used for ambient-pressure calorimetry. The second alloy (sample \#4) was first used for ambient-pressure calorimetry and $\mathrm{x}$-ray diffraction, and then for pressure-dependent calorimetry.

Using a Hitachi TM 3000 Tabletop scanning electron microscope, the formation of cracks was confirmed in a ribbon of $\mathrm{MnCoGeB}_{0.03}$ (sample \#3) that was fabricated as by melt-spinning under argon, as described in refs ${ }^{25,42}$. The ribbon did not require any polishing of the brittle specimen prior to microscopy.

X-ray diffraction spectra were collected using two different diffractometers. For low-temperature measurements, we used a Bruker D8 Discovery equipped with an Oxford PheniX cooler. For high-temperature measurements, we used an X'pert Philips equipped with a TCU 100 Temperature Control Unit manufactured by Anton Paar. Multiphase pattern matching and Rietveld refinement were performed using HighScore software.

Magnetization measurements were performed using a Quantum Design Dynacool vibrating sample magnetometer, while sweeping the temperature at $\pm 1 \mathrm{~K} \mathrm{~min}^{-1}$.

Measurements of $\mathrm{dQ} / \mathrm{d} T$ were performed at atmospheric pressure in a commercial TA Q2000 differential scanning calorimeter. Values of specific heat capacity outside the transition region were obtained by sweeping the temperature at $\pm 5 \mathrm{~K} \mathrm{~min}^{-1}$, recording the endothermic/exothermic heat flow with respect to the sample, and making comparison with the endothermic/exothermic heat flow with respect to the sapphire reference measured likewise $^{43}$. The latent heat $\left|Q_{0}\right|=\left|\int_{T_{1}}^{T_{2}} \frac{\mathrm{d} Q}{\mathrm{~d} T} \mathrm{~d} T\right|$ across the PM/O-FM/H transition was obtained after subtracting baseline backgrounds, with start temperature $T_{1}$ freely chosen below (above) 


\section{WILEY-VCH}

the transition on heating (cooling), and finish temperature $T_{2}$ freely chosen above (below) the transition on heating (cooling).

Measurements of $\mathrm{d} Q / \mathrm{d} T$ at constant applied pressure were performed using two bespoke differential thermal analysers. For applied pressures up to $0.3 \mathrm{GPa}$, we used a $\mathrm{Cu}-\mathrm{Be}$ Bridgman pressure cell with chromel-alumel thermocouples. For applied pressures up to 0.6 GPa, we used a model MV1-30 high-pressure cell (Institute of High Pressure Physics, Polish Academy of Science) with Peltier elements as thermal sensors. The temperature of these pressure cells was controlled using a circulating thermal bath (Lauda Proline RP 1290) that permitted the measurement temperature to be varied at around $\pm 2 \mathrm{~K} \mathrm{~min}^{-1}$ in $183-473 \mathrm{~K}$. The $\sim 3 \mathrm{~g}$ sample of $\mathrm{MnCoGeB}_{0.03}$ was mixed with an inert perfluorinated liquid (Galden, Bioblock Scientist) to remove any residual air, and hermetically encapsulated in containers of Sn. The pressure-transmitting medium was DW-Therm (Huber Kältemaschinenbau GmbH). The entropy change $\left|\Delta S_{0}(p)\right|=\left|\int_{T_{1}}^{T_{2}}(\mathrm{dQ} / \mathrm{d} T) / T \mathrm{~d} T\right|$ for the PM/H-FM/O transition was obtained after subtracting baseline backgrounds, with $T_{1}$ and $T_{2}$ chosen as explained above, repeatedly [Supporting Figure S3].

\section{Acknowledgements}

This work was supported by the MINECO project FIS2017-82625-P, the AGAUR project 2017SGR-0042, the Laboratorio Nacional de Investigaciones en Nanociencias y Nanotecnología (LINAN), the Division de Materiales Avanzados, and ERC Starting Grant No. 680032 (X. M.). We thank B.A. Rivera-Escoto for assisting with the preliminary $\mathrm{x}$-ray diffraction measurements. C. F. S. V. is grateful for the support from DMCU-UACJ. X. M. is grateful for support from the Royal Society.

\section{References}

[1] V. K. Pecharsky and K. A. Gschneidner Jr, J. Magn. Magn. Mater. 1999, 200, 44.

[2] K. A. Gschneidner, V. K. Pecharsky, and A. O. Tsokol, Rep. Prog. Phys. 2005, 68, 1479.

[3] E. Brück, J. Phys. D 2005, 38, R381. 


\section{WILEY-VCH}

[4] A. Planes, Ll. Mañosa, and M. Acet, J. Phys.: Condens. Matter 2009, 21, 233201.

[5] O. Gutfleisch, M. A. Willard, E. Brück, C. H. Chen, S. G. Sankar, and J. P. Liu, Adv. Mat. 23, 821 (2010).

[6] V. Franco, J. S. Blázquez, B. Ingale, and A. Conde, Annu. Rev. Mater. Res. 42, 305 (2012).

[7] A. Smith, C. R. H. Bahl, R. Bjørk, K. Engelbrecht, K. K. Nielsen, and N. Pryds, Adv. Energy Mater. 2, 1288 (2012).

[8] V. Franco, J. S. Blazquez, J. J. Ipus, J. Y. Law, L. M. Moreno-Ramirez, and A. Conde, Prog. Mater. Sci. 93, 112 (2018).

[9] X. Moya, S. Kar-Narayan, and N. D. Mathur, Nat. Mater. 13, 439 (2014).

[10] S. Crossley, N. D. Mathur, and X. Moya, AIP Advances 5, 067153 (2015).

[11] W. B. Cui, X. K. Lv, F. Yang, Y. Yu, R. Skomski, X. G. Zhao, W. Liu, and Z. D. Zhang, J. Appl. Phys. 107, 09A938 (2010).

[12] J. Torrens-Serra, C. A. Biffi, R. Santamarta, V. Recarte, J. I. Pérez-Landazábal, A. Tuissi, and E. Cesari, Mater. Charact. 93 24-31 (2014).

[13] A. Waske, L. Giebeler, B. Weise, A. Funk, M. Hinterstein, M. Herklotz, K. Skokov, S. Fähler, O. Gutfleisch, and J. Eckert J, Phys. Status Solidi RRL 9, 136 (2015).

[14] A. Waske, E. Lovell, A. Funk, K. Sellschopp, A. Rack, L. Giebeler, P. F. Gostin, S. Fähler, and L. F. Cohen, APL Materials 4, 106101 (2016).

[15] O. Gutfleisch, T. Gottschall, M. Fries, D. Benke, I. Radulov, K. P. Skokov, H. Wende, M. Gruner, M. Acet, P. Entel, and M. Farle, Phil. Trans. R. Soc. A 374, 20150308 (2016).

[16] Ll. Mañosa and A. Planes, Adv. Mater. 291603607 (2017). 


\section{WILEY-VCH}

[17] Ll. Mañosa, D. González-Alonso, A. Planes, E. Bonnot, M. Barrio, J.-Ll. Tamarit, S. Aksoy, and M. Acet, Nat. Mater. 9, 478 (2010).

[18] Ll. Mañosa, D. González-Alonso, A. Planes, M. Barrio, J.-Ll. Tamarit, I. S. Titov, M. Acet, A. Bhattacharyya, and S. Majumdar, Nat. Commun. 2, 595 (2011).

[19] S. Yuce, M. Barrio, B. Emre, E. Stern-Taulats, A. Planes, J.-Ll. Tamarit, Y. Mudryk, K. A. Gschneidner Jr, V. K. Pecharsky, and Ll. Mañosa, Appl. Phys. Lett. 101, 071906 (2012).

[20] E. Stern-Taulats, A. Planes, P. Lloveras, M. Barrio, J.-Ll. Tamarit, S. Pramanick, S. Majumdar, C. Frontera, and Ll. Mañosa, Phys. Rev. B 89, 214105 (2014).

[21] R.-R. Wu, L.-F. Bao, F.-X. Hu, H. Wu, Q.-Z. Huang, J. Wang, X.-L. Dong, G.-N. Li, J.-R. Sun, F.-R. Shen, T.-Y. Zhao, X.-Q. Zheng, L.-C. Wang, Y. Liu, W.-L. Zuo, Y.-Y. Zhao, M. Zhang, X.-C. Wang, C.-Q. Jin, G.-H. Rao, X.-F. Han, and B.-G. Shen, Sci. Rep. 518027 (2015).

[22] D. Matsunami, A. Fujita, K. Takenaka, and M. Kano, Nat. Mater. 14, 73 (2014).

[23] T. Samanta, P. Lloveras, A. U. Saleheen, D. L. Lepkowski, E. Kramer, I. Dubenko, P. W. Adams, D. P. Young, M. Barrio, J. Ll. Tamarit, N. Ali, and S. Stadler, Appl. Phys. Lett. 112, 021907 (2018).

[24] N. T. Trung, L. Zhang, L. Caron, K. H. J. Buschow, and E. Brück, Appl. Phys. Lett. 96 172504 (2010).

[25] G. Daniel-Pérez, J. L. Sánchez Llamazares, P. Alvarez-Alonso, C. F. Sánchez-Valdés, R. Varga, V. Chernenko, and A. Quintana-Nedelcos, J. Magn. Magn. Mater. 444263 (2017).

[26] F. Zhu, J. C. Lina, W. B. Jiang, C. Yang, L. F. Li, X. K. Zhang, W. H. Song, X. B. Zhu, P. Tong, and Y. P. Sun, Scr. Mater. 150, 96 (2018). 


\section{WILEY-VCH}

[27] E. Stern-Taulats, T. Castán, Ll. Mañosa, A. Planes, N. D. Mathur, and X. Moya, MRS Bulletin 43, 295 (2018).

[28] S. Lin, O. Tegus, E. Brück, W. Dagula, T. J. Gortnemulder, and K. H. J. Buschow, IEEE Trans. Magn. 42, 3776 (2006).

[29] L. Caron, N. T. Trung, and E. Brück, Phys. Rev. B 84 020414(R)

[30] N. T. Trung, First-order phase transitions and giant magnetocaloric effect, Technische Universiteit Delft (2010).

[31] G. F. Wang, Magnetic and calorimetric study of the magnetocaloric effect in intermetallics exhibiting first-order magnetostructural transitions, Universidad de Zaragoza (2012).

[32] A. Bartok, M. Kustov, L. F. Cohen, A. Pasko, K. Zehani, L. Bessais, F. Mazaleyrat, and M. LoBue, J. Magn. Magn. Mat. 400, 333 (2016).

[33] S. Kapryzk and S. Niziol, J. Magn Magn Mater. 87, 267 (1990).

[34] P. Lloveras, E. Stern-Taulats, M. Barrio, J.-Ll. Tamarit, S. Crossley, W. Li, V. Pomjakushin, A. Planes, Ll. Mañosa, N. D. Mathur and X. Moya, Nat. Commun.6, 8801 (2015).

[35] P. E. Markin, N. V. Mushnikov, A. V. Proshkin, and S. V. Belyaev, Sol. State Phenom. 190, 331 (2012).

[36] K.A. Gschneidner Jr, Y. Mudryka, and V.K. Pecharsky, Scr. Mater. 67, 572 (2012).

[37] E. Stern-Taulats, P. Lloveras, M. Barrio, E. Defay, M. Egilmez, A. Planes, J.-Ll. Tamarit, Ll. Mañosa, N. D. Mathur, and X. Moya, APL Mater. 4, 091102 (2016).

[38] I. N. Flerov, A. V. Kartasheva, M. V. Gorev, E. V. Bogdanov, S. V. Mel'nikova, M. S. Molokeev, E. I. Pogoreltsev, and N. M. Laptashf, J. Fluorine Chem. 183, 1 (2016). 


\section{WILEY-VCH}

[39] J. M. Bermúdez-García, M. Sánchez-Andújar, S. Castro-García, J. López-Beceiro, R. Artiaga and M. A. Señarís-Rodríguez, Nat. Commun. 8, 15715 (2017).

[40] A. Aznar, P. Lloveras, M. Romanini, M. Barrio, J.-Ll. Tamarit, C. Cazorla, D. Errandonea, N. D. Mathur, A. Planes, X. Moya, and Ll. Mañosa, Nat. Commun. 8, 1851 (2017).

[41] J. M. Bermúdez-García, S. Yáñez-Vilar, A. García-Fernández, M. Sánchez-Andújar, S. Castro-García, J. López-Beceiro, R. Artiaga, M. Dilshad, X. Moya, and M. A. SeñarísRodríguez, J Mater. Chem. C 6, 9867 (2018).

[42] A. Quintana-Nedelcos, J. L. Sánchez Llamazares, and H. Flores-Zuñiga J. Alloys Compd 644, 1003 (2015).

[43] M. J. O’Neill, Anal. Chem. 38, 1331 (1966). 


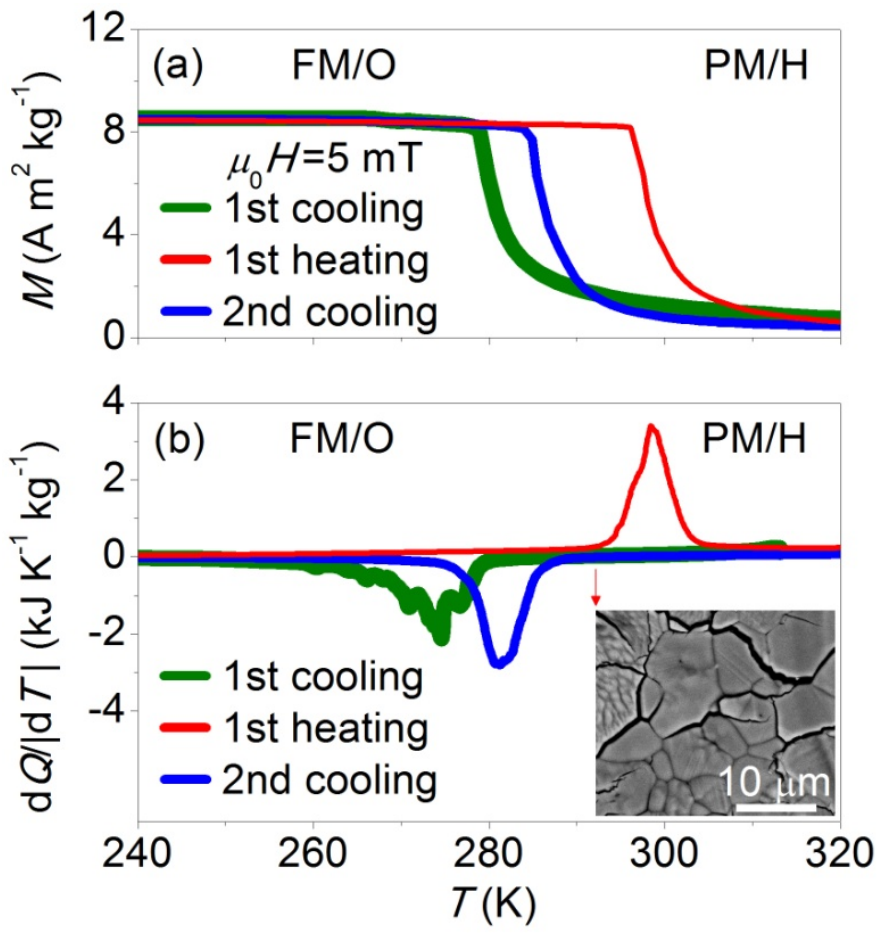

Figure 1. Virgin effects in $\mathrm{MnCoGeB}_{0.03}$. (a) Low-field magnetisation $M$ measured in $\mu_{0} \mathrm{H}=5 \mathrm{mT}$ across the paramagnetic/hexagonal-ferromagnetic/orthorhombic (PM/H-FM/O) phase transition on the first cooling run (green), the first heating run (red), and the second cooling run (blue). Below the magnetostructural transition, the sample exists as a mixture of the majority FM/O phase and the minority PM/H phase [ref. ${ }^{24}$ and Supporting Figure S1]. (b) Heat flow $\mathrm{d} Q /|\mathrm{d} T|$ after subtracting baseline backgrounds, measured in zero magnetic field via the same thermal sequence $(\mathrm{d} Q /|\mathrm{d} T|>0$ denotes endothermic processes). Inset: scanning electron microscopy image of the sample after cooling and then heating to room temperature, as indicated by the red arrow. Magnetometry data for sample \#1, calorimetry data for sample \#2, microscopy data for sample \#3. 


\section{WILEY-VCH}
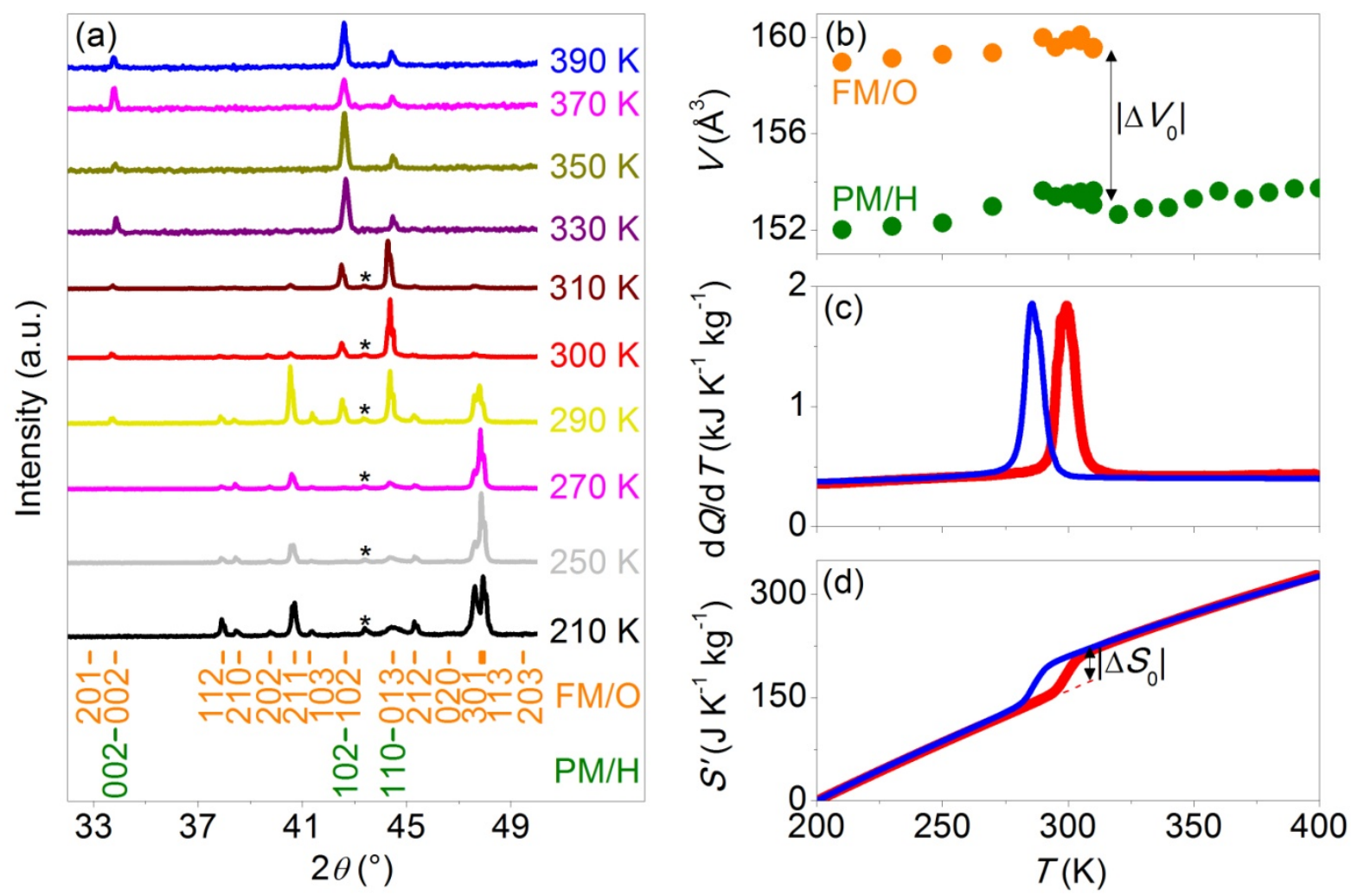

Figure 2. Magnetostructural transition in $\mathrm{MnCoGeB}_{0.03}$ at ambient pressure. (a) Detail of selected $\mathrm{x}$-ray diffraction spectra obtained across the $\mathrm{FM} / \mathrm{O}-\mathrm{PM} / \mathrm{H}$ transition on heating, at atmospheric pressure. Vertical orange lines indicate indexed Bragg reflections for the ferromagnetic/orthorhombic FM/O phase at $210 \mathrm{~K}$; vertical green lines indicate indexed reflections for the paramagnetic/hexagonal $\mathrm{PM} / \mathrm{H}$ phase at $210 \mathrm{~K}$; asterisks indicate a reflection from the $\mathrm{Cu}$ sample holder. The complete dataset is available in the Supporting Information. Hence (b) the unit-cell volume $V$ on decreasing temperature $T$, revealing a large volume change $\left|\Delta V_{0}\right|$ for the transition. On heating (red) and cooling (blue) across the transition, (c) dQ/dT shows a large latent heat and (d) entropy $S^{\prime}(T)=S(T)-S(200 \mathrm{~K})$ shows a large entropy change $\left|\Delta S_{0}\right|$. Here, $S^{\prime}(T)$ was evaluated using $S^{\prime}(T)=S(T)-S(200 \mathrm{~K})=\int_{200 \mathrm{~K}}^{T}(1 / T)\left(\mathrm{d} Q / \mathrm{d} T^{\prime^{\prime}}\right) \mathrm{d} T^{\prime}$. All data for sample \#4. 
WILEY-VCH
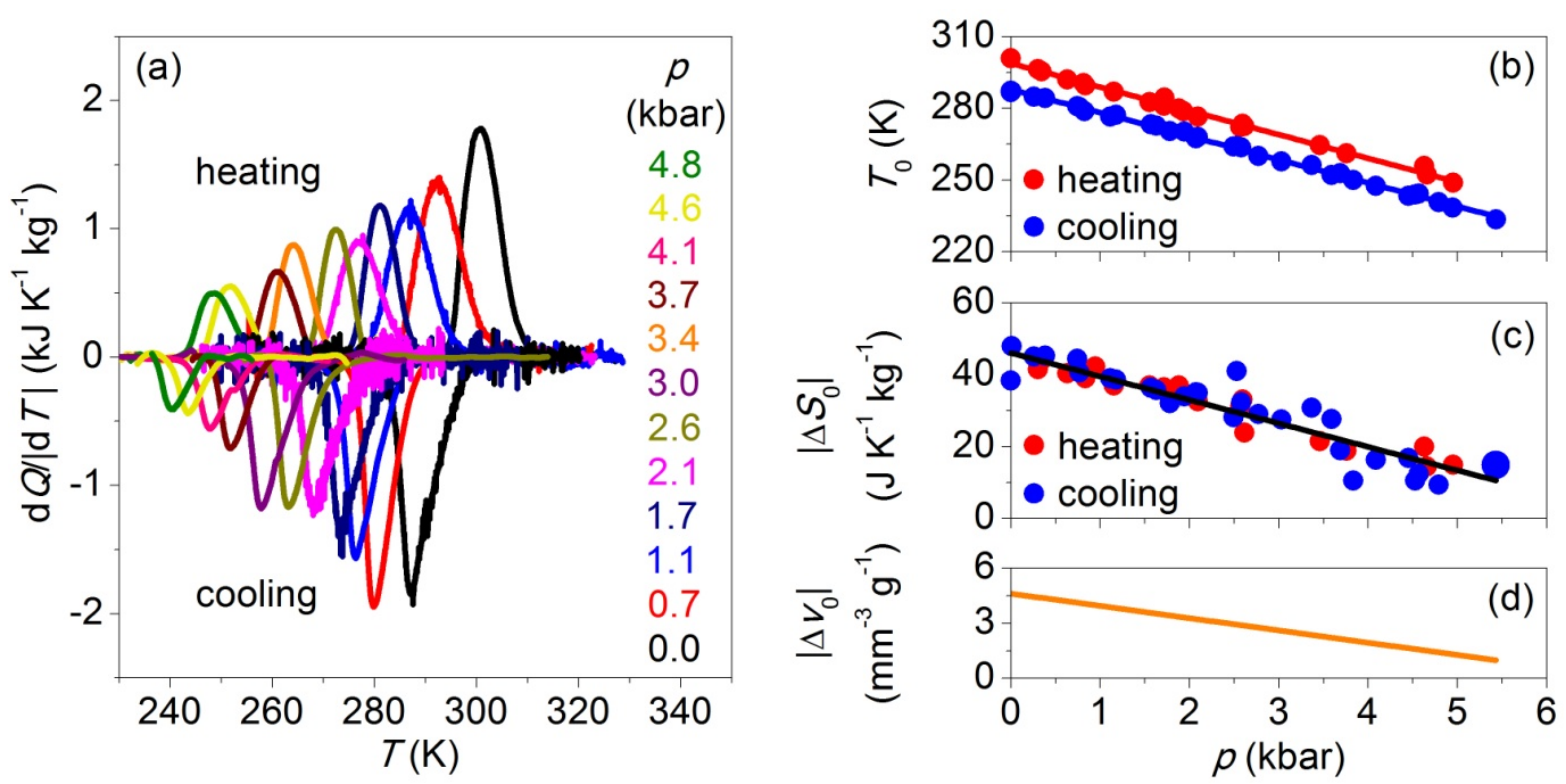

Figure 3. Magnetostructural phase transition in $\mathrm{MnCoGeB}_{0.03}$ under pressure. (a) Heat flow $\mathrm{dQ} /|\mathrm{d} T|$ on cooling and heating across the $\mathrm{PM} / \mathrm{H}-\mathrm{FM} / \mathrm{O}$ transition, after baseline subtraction, for different values of increasing pressure $p$. Pressure dependence of (b) transition temperature $T_{0}$ and (c) entropy change $\left|\Delta S_{0}\right|$. Lines in (b) and (c) are linear fits to data obtained on cooling (blue symbols) and heating (red symbols). (d) Volume change $\left|\Delta V_{0}(p)\right|$ for the sample across the transition, obtained from (b,c) via the Clausius-Clapeyron equation. All data for sample \#4. 
WILEY-VCH
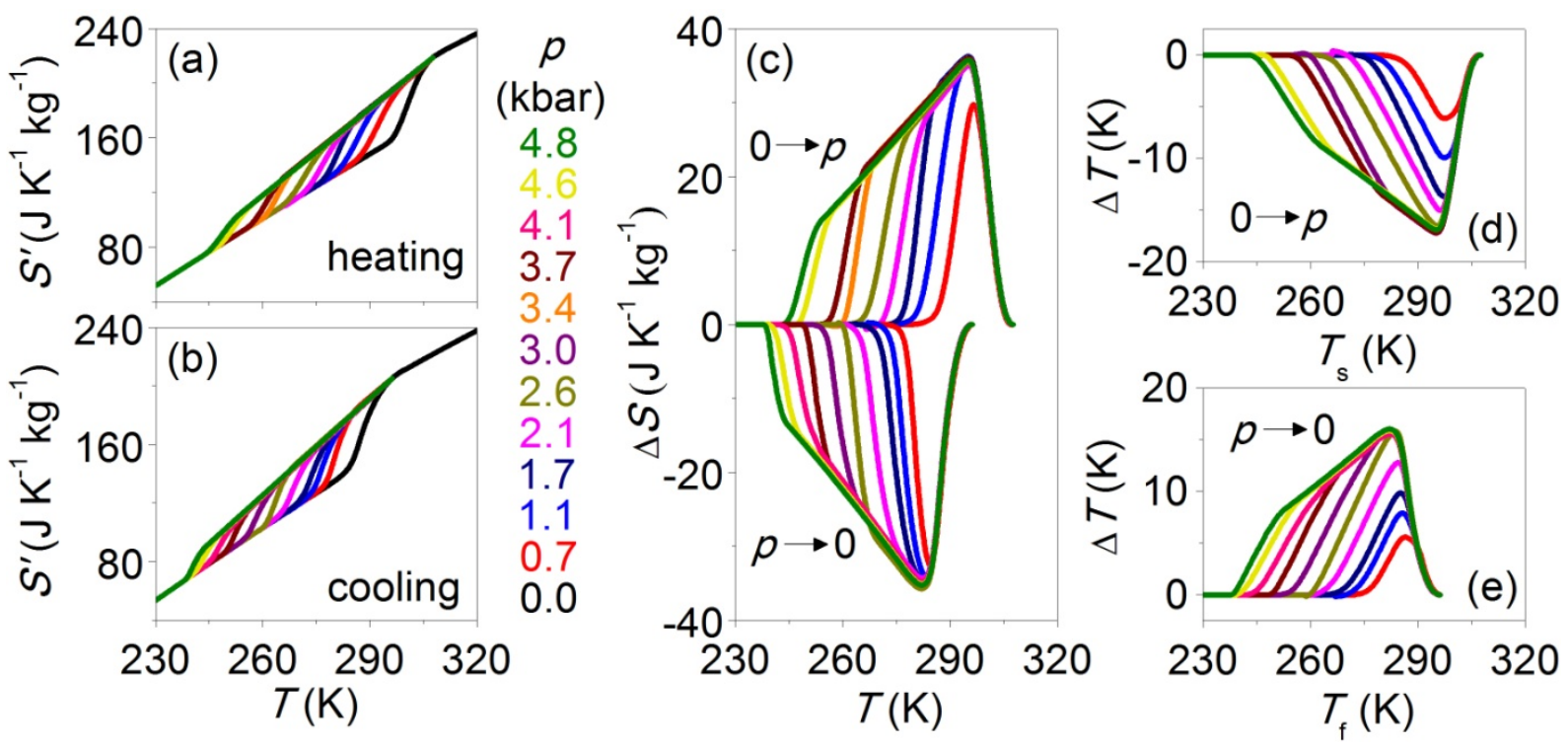

Figure 4. Giant and reversible inverse $B C$ effects in $\operatorname{MnCoGeB}_{0.03}$. (a,b) Entropy $S^{\prime}(T, p)$ on (a) heating and (b) cooling through the $\mathrm{PM} / \mathrm{H}-\mathrm{FM} / \mathrm{O}$ phase transition, given with respect to the absolute entropy at $200 \mathrm{~K}$ and $p \sim 0$. (c) Isothermal entropy change $\Delta S$ for $0 \rightarrow p$ deduced from (a), and for $p \rightarrow 0$ deduced from (b). (d) Adiabatic temperature change $\Delta T$ versus starting temperature $T_{\mathrm{s}}$ for $0 \rightarrow p$ deduced from (a). (e) Adiabatic temperature change $\Delta T$ versus finishing temperature $T_{\mathrm{f}}$ for $p \rightarrow 0$ deduced from (b). Reversibility in $\Delta S$ and $\Delta T$ is apparent below the zero-pressure transition start temperature $T_{\text {cool1 }} \sim 290 \mathrm{~K}$ on cooling. All data for sample \#4. 